\title{
Sewing Machine Selection Using Linear Physical Programming
}

\author{
Mehmet Ali Ilgın \\ Manisa Celal Bayar University, Department of Industrial Engineering, Manisa, Turkey
}

Corresponding Author: Mehmet Ali Ilgın, mehmetali.ilgin@cbu.edu.tr

\begin{abstract}
Sewing is a critical operation in garment production process. Therefore, alternative sewing machines must carefully be evaluated prior to procurement. Multiple criteria decision making (MCDM) techniques can effectively be used in sewing machine evaluation process since multiple evaluation criteria including speed and price must be considered. However, physically meaningless subjective weights are assigned to evaluation criteria in most MCDM techniques. Linear Physical Programming (LPP) is a MCDM methodology that eliminates this subjective weight assignment process by allowing decision makers to express their preferences in a physically meaningful way. In this study, a sewing machine selection problem faced by a textile company is solved using LPP.
\end{abstract}

\author{
ARTICLE HISTORY \\ Received: 13.08.2018 \\ Accepted: 15.10.2019

\section{KEYWORDS} \\ multiple criteria decision \\ making, linear physical \\ programming, sewing, \\ machine selection, textile \\ company
}

\section{INTRODUCTION}

Sewing is one of the most critical operations in garment production [1, 2]. Industrial sewing operations are usually carried out by using industrial sewing machines. There are many industrial sewing machine alternatives since various companies produce many different types of industrial sewing machines. Hence a textile company must evaluate those alternatives by considering multiple criteria including price, speed, weight and power consumption.

Multi-criteria decision making techniques were commonly used in industrial sewing machine evaluation due to the above-mentioned multi-criteria nature of the problem. Ertuğrul and Öztaş, 2015 applied MOORA (multi-objective optimization on the basis of ratio analysis) and TOPSIS (Technique for Order Preference by Similarity to Ideal Solution) multi criteria decision making techniques to a sewing machine selection problem [3]. The rankings proposed by those two techniques were compared. Ulutaş, 2017 employed EDAS (Evaluation based on Distance from Average Solution) for the evaluation of alternative sewing machines for a textile company [4].
The weights for the evaluation criteria were assigned subjectively in both of the above-cited studies. In this study, the subjective weight assignment process is eliminated by using linear physical programming (LPP). In LPP, the decision maker expresses his/her preferences for each criterion in a flexible and natural way. Then a weight algorithm is used to determine the criteria weights based on the preferences of the decision maker.

The rest of the paper is organized as follows. Section 2 provides brief information on LPP. The details on the application of LPP to a sewing machine selection problem faced by a company are presented in section 3. Finally, conclusions and future research directions are presented in section 4.

\section{LINEAR PHYSICAL PROGRAMMING}

Linear Physical Programming (LPP) was proposed by Messac et al., 1996 as an alternative to traditional optimization techniques [5]. LPP lets the decision maker define a multi objective decision making problem in a natural and flexible way. The decision maker can use one of 
the following four LPP classes for each criterion in the problem formulation [6, 7]: $1 \mathrm{~S}$ (smaller is better), 2S (larger is better), 3S (value is better) and $4 \mathrm{~S}$ (range is better). Figure 1 presents the LPP classes. The horizontal axis in this figure represents the preference ranges. These ranges can be presented for Class $2 \mathrm{~S}$ as follows:

- Unacceptable range

$$
\begin{aligned}
& : c_{k} \leq s_{k 5}^{-} \\
& : s_{k 5}^{-} \leq c_{k} \leq s_{k 4}^{-} \\
& : s_{k 4}^{-} \leq c_{k} \leq s_{k 3}^{-} \\
& : s_{k 3}^{-} \leq c_{k} \leq s_{k 2}^{-} \\
& : s_{k 2}^{-} \leq c_{k} \leq s_{k 1}^{-}
\end{aligned}
$$

- Highly undesirable range

- Undesirable range

- Tolerable range

- Desirable range

- Ideal range$$
: c_{k} \geq s_{k 1}^{-}
$$

The quantities $s_{k 1}^{-}$through $s_{k 5}^{-}$are specified by the decision maker for the $k^{\text {th }}$ generic criterion. Let us assume that the decision maker specifies the values of $s_{k 1}^{-}$through $s_{k 5}^{-}$as $300,250,200,150,100$, respectively. If the criterion value of an alternative is 280 , it would locate in the desirable range. If the criterion value is 180 , it would be in the undesirable range [8].

The class function $f_{k}$ is presented on the vertical axis. Criteria values are mapped into non-dimensional, strictly positive real numbers using this function. In other words, the class function creates a common scale with dimensionless values for each criterion. Considering Class $2 \mathrm{~S}$ as an example, we can see that the value of the class function is very small if the criterion value is in the desirable range. If the criterion value is in the highly undesirable range, the value of the class function becomes too large.

The application steps of LPP can be presented as follows:

1. Appropriate class functions are determined for the criteria.

2. The limits for the desirability ranges are determined.

3. The following LPP weight algorithm [5] is employed for the calculation of the incremental weights:
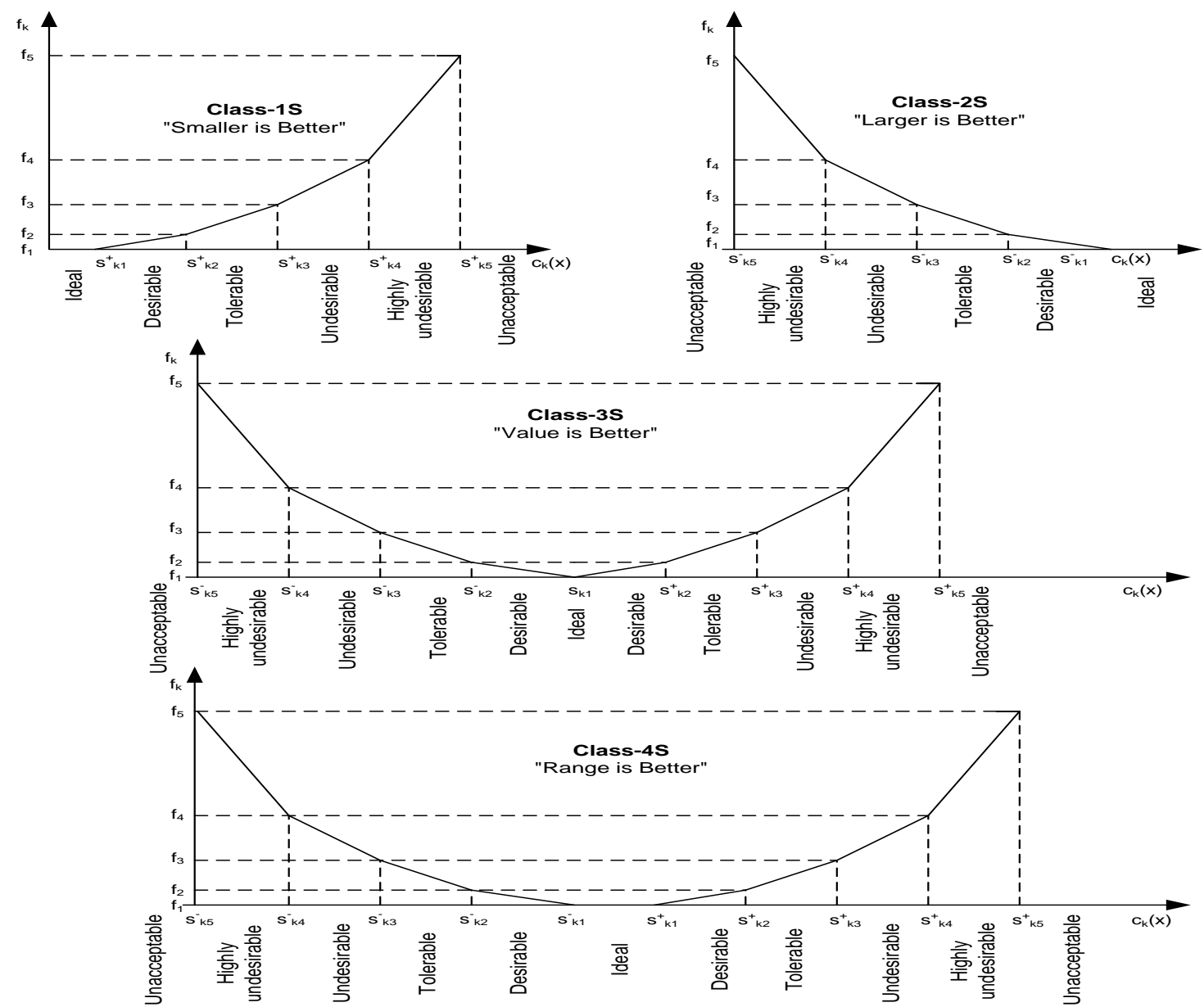

Figure 1. Classes in LPP

3.1. Initialize:

$\beta=1.1, w_{k 1}^{+}=0, w_{k 1}^{-}=0, \tilde{f}^{2}=$ small positive number (say, 0.01 ), $k=0 ; j=1, N C$ : number of criteria.
3.2. Set $k=k+1$

3.3. Set $j=j+1$

Evaluate, in sequence, 


$$
\tilde{f}^{j}, \tilde{s}_{k j}^{+}, \tilde{s}_{k j}^{-}, w_{k j}^{+}, w_{k j}^{-}, \tilde{w}_{\min }
$$

If $\tilde{w}_{\text {min }}$ is less than a small positive number (say, 0.01 ), then increase $\beta$, and go to 3.2.

3.4. If $j \neq 5$, go to 3.3 .

\subsection{If $k \neq N C$, go to 3.2 .}

where $k$ represents criterion, $j$ represents range, $\beta$ is a parameter of convexity (see [5]), $f_{k}$ is the class function for the criterion $k, \tilde{f}^{j}$ represents the change in $f_{k}$ that occurs as one travels across the range $j, \tilde{s}_{k j}^{-}$and $\tilde{s}_{k j}^{+}$represent the widths of the $j^{\text {th }}$ ranges on the negative and positive sides of criterion $k, w_{k j}^{-}$and $w_{k j}^{+}$are negative and positive weights, respectively, for the range $j$ of criterion $k$ and $\tilde{w}_{\min }$ is the minimum of $w_{k j}^{-}$and $w_{k j}^{+}$.

In class function, the slope increments between different desirability ranges are represented with positive and negative weights [7]. The following equations can be used for the calculation of those weights:

$$
\begin{gathered}
w_{k j}^{+}=\frac{\tilde{f}^{j}}{\tilde{s}_{k j}^{+}} \\
w_{k j}^{-}=\frac{\tilde{f}^{j}}{\tilde{s}_{k j}^{-}}
\end{gathered}
$$

In those equations, $\tilde{f}^{j}, \tilde{s}_{k j}^{+}$and $\tilde{s}_{k j}^{-}$are calculated as follows:

$$
\begin{aligned}
& \tilde{f}^{j}=\beta(N C-1) \tilde{f}^{j-1} \\
& \tilde{s}_{k j}^{+}=s_{k j}^{+}-s_{k(j-1)}^{+} \\
& \tilde{s}_{k j}^{-}=s_{k j}^{-}-s_{k(j-1)}^{-}
\end{aligned}
$$

4. A total score $(T)$ for each alternative is calculated by taking the weighted sum of deviations:

$$
\min _{d_{\bar{k}}^{-}, d_{k j}^{+}} T=\sum_{k=1}^{N C} \sum_{j=2}^{5}\left(w_{k j}^{-} \cdot d_{k j}^{-}+w_{k j}^{+} \cdot d_{k j}^{+}\right)
$$

where $d_{k j}^{-}$and $d_{k j}^{+}$represent the deviations from the corresponding target values for the $k^{\text {th }}$ criterion value of the alternative of interest. Alternatives are ranked using total scores. The best alternative is the one with the lowest total score value.

LPP-based solution methodologies were developed in order solve various problems in different domains including production planning [9], reverse logistics [10] and robot selection [11]. The interested reader is referred to a comprehensive review by Ilgin and Gupta, 2012 for more information on LPP applications [6].

\section{INDUSTRIAL SEWING MACHINE SELECTION USING LPP}

This section presents the application of LPP to a sewing machine selection problem faced by a textile company. The company tries to determine the most suitable single-needle lockstitch industrial sewing machine. The following five evaluation criteria were determined by interviewing the managers of the company:

- Price: Average market price in dollars (\$) was used. Price must be minimized in order to minimize the total cost of investment.

- Power Consumption: The company prefers industrial sewing machines with low power consumption in order to minimize its energy costs. The unit for power consumption is Volt-Amperes (VA).

- Weight: The weight of machine head in kilogram $(\mathrm{kg})$ was considered as a criterion. The weight should be as low as possible for ease of transportation.

- Maximum Speed: Maximum speed in stitches per minute (spm) was considered as a criterion. Maximum speed of the machine should be as high as possible.

- After-sale Support: The quality of the after-sale support services offered by a sewing machine manufacturer is a vital criterion. This criterion is evaluated using a 10point scale (10 being the highest after-sale support and 1 being the lowest after-sale support).

Table 1 presents the criteria values for the eight alternative industrial sewing machines (ISM) considered in this study. Target values for each criterion were presented in Table 2. Those values were determined by interviewing the managers of the company. The three criteria (Price, Power Consumption and Weight) were modeled as Class 1S while the other two criteria (Maximum Speed and After-sale Support) were modeled as Class 2S.

$\mathrm{C}++$ programming language was used to code the LPP weight algorithm and the criteria weights presented in Table 3 were obtained using this algorithm. A screenshot from this algorithm is presented in Figure 2.

An LPP model for each ISM was constructed using Lingo (v17) mathematical programming software. Deviations from the target values for each ISM were determined using this model. As an example, deviations for ISM 1 are presented in Table 4. For instance, consider the first criterion (price - $f_{1}$ ). The deviation for $j=2$ can be determined in two steps. First, the value of the criterion (i.e., 1495, see the bolded number in Table 1) is subtracted from the target value (i.e., 1250; see the bolded number in Table 2). Then the absolute value (i.e., 245, see the bolded number in Table 4) of this difference is taken.

The total score for each ISM (see Table 5) was determined by solving the associated LPP model. For instance, the total score for ISM 1 is calculated by using the deviations from Table 4 and the criteria weights from Table 3:

Total_Score ISM $1=245 * 0.04+100 * 0.2+50 * 0.138462+7 * 2+$ $2 * 2.4+500 * 0.01+5 * 1=65.5231$

A ranking of alternative ISMs is also presented in Table 5 . ISM 1 with the lowest total score is the best ISM based on the preferences of the decision makers. 
Table 1. Characteristics of alternative ISMs

\begin{tabular}{|c|c|c|c|c|c|}
\hline Machines & $\begin{array}{c}\text { Price } \\
\mathbf{( \$ )}\end{array}$ & $\begin{array}{c}\text { Power } \\
\text { Consumption (VA) }\end{array}$ & $\begin{array}{c}\text { Weight } \\
\mathbf{( k g )}\end{array}$ & Maximum Speed (spm) & $\begin{array}{c}\text { After-sale } \\
\text { Support }\end{array}$ \\
\hline ISM 1 & $\mathbf{1 4 9 5}$ & 400 & 37 & 5000 & 8 \\
\hline ISM 2 & 1800 & 415 & 46 & 5000 & 6 \\
\hline ISM 3 & 2150 & 520 & 40.5 & 5000 & 6 \\
\hline ISM 4 & 1300 & 250 & 36 & 4000 & 6 \\
\hline ISM 5 & 2049 & 320 & 30 & 5000 & 6 \\
\hline ISM 6 & 1825 & 450 & 34.5 & 5000 & 6 \\
\hline ISM 7 & 2079 & 390 & 28 & 5500 & 6 \\
\hline ISM 8 & 1850 & 320 & 38 & 5000 & \\
\hline
\end{tabular}

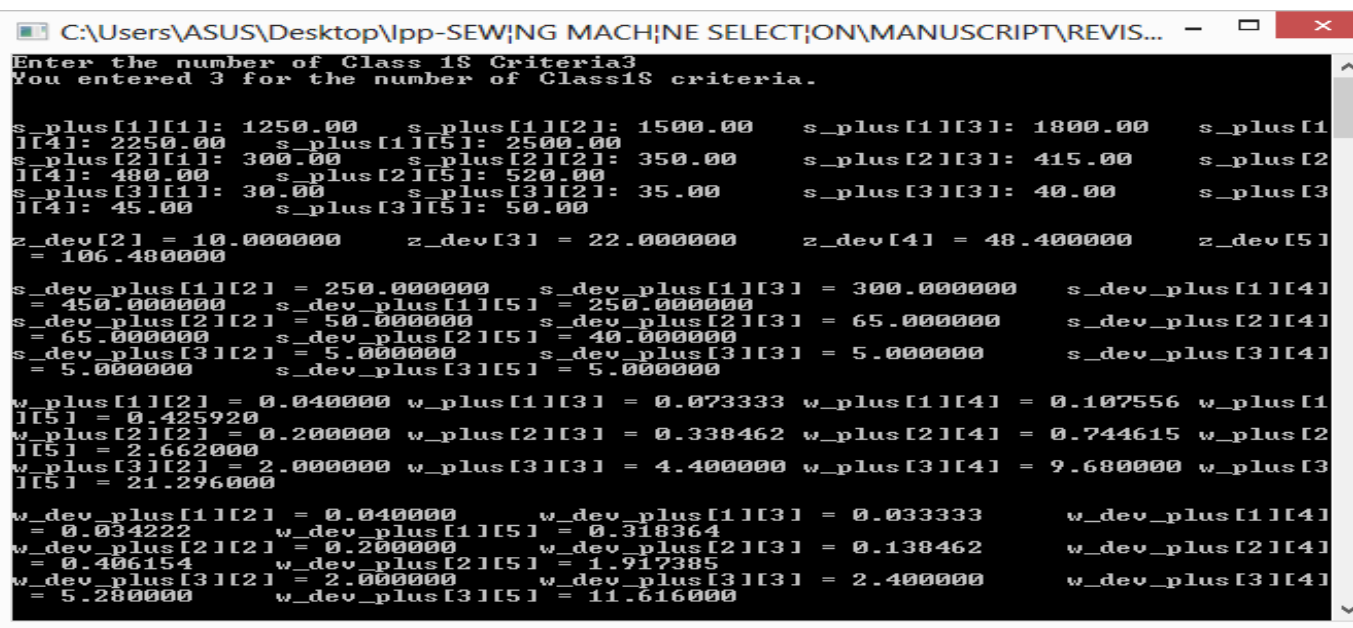

Figure 2. A screenshot from the weight algorithm

Table 2. Target values for the evaluation criteria

\begin{tabular}{|c|c|c|c|}
\hline \multicolumn{4}{|l|}{ Criterion 1 $(k=1)$ : Price } \\
\hline Class 1S & $\begin{array}{c}\text { Preference } \\
\text { Range }\end{array}$ & Limit & $\begin{array}{c}\text { Limit } \\
\text { Value }\end{array}$ \\
\hline Preference & $\leq \mathrm{s}^{-} 11$ & $\mathrm{~s}^{-} 11$ & $\mathbf{1 2 5 0}$ \\
\hline I & $\left(\mathrm{s}^{-} 11, \mathrm{~s}^{-} 12\right)$ & $\mathrm{s}^{-} 12$ & 1500 \\
\hline D & $\left(\mathrm{s}^{-} 12, \mathrm{~s}^{-} 13\right)$ & $\mathrm{s}^{-} 13$ & 1800 \\
\hline T & $\left(\mathrm{s}^{-} 13, \mathrm{~s}^{-} 14\right)$ & $\mathrm{s}^{-} 14$ & 2250 \\
\hline UD & $\left(\mathrm{s}^{-} 14, \mathrm{~s}^{-} 15\right)$ & $\mathrm{s}^{-} 15$ & 2500 \\
\hline HU & $\geq \mathrm{s}^{-} 15$ & & \\
\hline UA & & &
\end{tabular}

\section{Criterion ( $k=3)$ : Weight}

Class 1S

\begin{tabular}{|c|c|c|c|}
\hline Preference & $\begin{array}{c}\text { Preference } \\
\text { Range }\end{array}$ & Limit & $\begin{array}{l}\text { Limit } \\
\text { Value }\end{array}$ \\
\hline I & $\leq \mathrm{s}_{31}^{-}$ & $\mathrm{s}^{-} 31$ & 30 \\
\hline $\mathrm{D}$ & $\left(\mathrm{s}^{-}{ }_{31}, \mathrm{~s}_{32}{ }^{2}\right)$ & $\mathrm{s}_{32}^{-}$ & 35 \\
\hline $\mathrm{T}$ & $\left(\mathrm{s}^{-}{ }_{32}, \mathrm{~s}^{-}{ }_{33}\right)$ & $\mathrm{S}_{33}^{-3}$ & 40 \\
\hline UD & $\left(\mathrm{s}^{-} 33, \mathrm{~s}^{-}{ }^{-}\right)$ & $\mathrm{s}^{-} 34$ & 45 \\
\hline $\mathrm{HU}$ & $\left(\mathrm{s}^{-}{ }_{34}, \mathrm{~s}_{35}{ }_{35}\right)$ & $\mathrm{s}^{-} 35$ & 50 \\
\hline UA & $\geq \mathrm{s}^{-}{ }_{35}$ & & \\
\hline
\end{tabular}

Criterion 5 ( $k=5)$ : After-sale Support

\begin{tabular}{|c|c|c|c|}
\hline \multicolumn{4}{|l|}{ Class 2S } \\
\hline Preference & $\begin{array}{c}\text { Preference } \\
\text { Range }\end{array}$ & Limit & $\begin{array}{l}\text { Limit } \\
\text { Value }\end{array}$ \\
\hline I & $\geq \mathrm{s}^{+}{ }_{51}$ & $\mathrm{~s}^{+}{ }_{51}$ & 9 \\
\hline D & $\left(\mathrm{s}^{+}{ }_{51}, \mathrm{~s}^{+}{ }_{52}\right)$ & $\mathrm{S}^{+} 52$ & 7 \\
\hline $\mathrm{T}$ & $\left(\mathrm{s}^{+} 52, \mathrm{~s}^{+} 53\right)$ & $\mathrm{s}^{+} 53$ & 5 \\
\hline UD & $\left(\mathrm{s}^{+}{ }_{53}, \mathrm{~S}^{+}{ }_{54}\right)$ & $\mathrm{S}^{+}{ }_{54}$ & 3 \\
\hline $\mathrm{HU}$ & $\left(\mathrm{s}^{+}{ }_{54}, \mathrm{~s}^{+}{ }_{55}\right)$ & $\mathrm{s}_{55}^{+}$ & 1 \\
\hline UA & $\leq \mathrm{s}^{+} 55$ & & \\
\hline
\end{tabular}

Criterion $2(k=2)$ :Power Consumption Class $1 \mathrm{~S}$

\begin{tabular}{|c|c|c|c|}
\hline Preference & $\begin{array}{c}\text { Preference } \\
\text { Range }\end{array}$ & Limit & $\begin{array}{l}\text { Limit } \\
\text { Value }\end{array}$ \\
\hline I & $\leq \mathrm{s}_{21}^{-}$ & $\mathrm{S}_{21}^{-}$ & 300 \\
\hline $\mathrm{D}$ & $\left(\mathrm{s}^{-} 21, \mathrm{~s}^{-} 22\right)$ & $\mathrm{S}^{-2} 22$ & 350 \\
\hline $\mathrm{T}$ & $\left(\mathrm{s}_{22}^{-}, \mathrm{s}_{23}{ }_{23}\right)$ & $\mathrm{S}_{23}^{-2}$ & 415 \\
\hline UD & $\left(\mathrm{s}_{23}^{-}, \mathrm{s}^{-}{ }_{24}\right)$ & $\mathrm{S}^{-24}$ & 480 \\
\hline $\mathrm{HU}$ & $\left(\mathrm{s}^{-} 24, \mathrm{~s}^{-} 25\right)$ & $\mathrm{s}^{2} 25$ & 520 \\
\hline UA & $\geq \mathrm{S}^{-}{ }_{25}$ & & \\
\hline
\end{tabular}

Criterion $4(k=4)$ : Maximum Speed Class 2S

\begin{tabular}{|c|c|c|c|}
\hline Preference & $\begin{array}{c}\text { Preference } \\
\text { Range }\end{array}$ & Limit & $\begin{array}{c}\text { Limit } \\
\text { Value }\end{array}$ \\
\hline I & $\geq \mathrm{s}^{+}{ }_{41}$ & $\mathrm{~s}^{+} 41$ & 5500 \\
\hline $\mathrm{D}$ & $\left(\mathrm{s}^{+} 41, \mathrm{~s}^{+}{ }_{42}\right)$ & $\mathrm{s}^{+} 42$ & 5000 \\
\hline $\mathrm{T}$ & $\left(\mathrm{s}^{+} 42, \mathrm{~s}^{+} 43\right)$ & $\mathrm{s}^{+} 43$ & 4500 \\
\hline UD & $\left(\mathrm{s}^{+}{ }_{43}, \mathrm{~s}^{+} 44\right)$ & $\mathrm{s}^{+} 44$ & 4000 \\
\hline HU & $\left(\mathrm{s}^{+} 44, \mathrm{~s}^{+} 45\right)$ & $\mathrm{s}^{+} 45$ & 3000 \\
\hline UA & $\leq \mathrm{s}^{+} 45$ & & \\
\hline \multicolumn{4}{|l}{} \\
\hline
\end{tabular}

I: Ideal

D: Desirable

T: Tolerable

UD: Undesirable

HU: Highly Undesirable

UA: Unacceptable 
Table 3. Weights for each criterion

\begin{tabular}{|l|c|c|c|c|c|c|c|c|}
\hline Criteria & $w_{k 2}^{+}$ & $w_{k 3}^{+}$ & $w_{k 4}^{+}$ & $w_{k 5}^{+}$ & $w_{k 2}^{-}$ & $w_{k 3}^{-}$ & $w_{k 4}^{-}$ & $w_{k 5}^{-}$ \\
\hline Price $(k=1)$ & 0.04 & 0.033333 & 0.034222 & 0.318364 & - & - & - & - \\
\hline $\begin{array}{l}\text { Power } \\
\text { Consumption } \\
(k=2)\end{array}$ & 0.2 & 0.138462 & 0.406154 & 1.917385 & - & - & - & - \\
\hline Weight $(k=3)$ & 2 & 2.4 & 5.28 & 11.616 & - & - & - & - \\
\hline $\begin{array}{l}\text { Max. Speed } \\
(k=4)\end{array}$ & - & - & - & - & 0.01 & 0.017400 & 0.010138 & 0.013889 \\
\hline $\begin{array}{l}\text { After-sale } \\
\text { Support }(k=5)\end{array}$ & - & - & - & - & 5 & 1.85 & 2.5345 & 3.472265 \\
\hline
\end{tabular}

Table 4. Deviations for ISM 1

\begin{tabular}{|l|c|c|c|c|}
\hline Criteria & $\boldsymbol{j}=\mathbf{2}$ & $\boldsymbol{j}=\mathbf{3}$ & $\mathbf{j = 4}$ & $\boldsymbol{j}=\mathbf{5}$ \\
\hline Price $(k=1)$ & $\mathbf{2 4 5}$ & 0 & 0 & 0 \\
\hline Power Consumption $(k=2)$ & 100 & 50 & 0 & 0 \\
\hline Weight $(k=3)$ & 7 & 2 & 0 & 0 \\
\hline Max. Speed $(k=4)$ & 500 & 0 & 0 & 0 \\
\hline After-sale Support $(k=5)$ & 1 & 0 & 0 & 0 \\
\hline
\end{tabular}

Table 5. Total scores and ranks of alternative ISMs

\begin{tabular}{|c|c|c|}
\hline Alternatives & Total Score & Rank \\
\hline ISM 1 & 65.5231 & 1 \\
\hline ISM 2 & 175.6959 & 7 \\
\hline ISM 3 & 315.2143 & 8 \\
\hline ISM 4 & 70.719 & 2 \\
\hline ISM 5 & 84.63109 & 3 \\
\hline ISM 6 & 111.7504 & 6 \\
\hline ISM 7 & 102.3962 & 5 \\
\hline ISM 8 & 86.42765 & 4 \\
\hline
\end{tabular}

\section{CONCLUSION}

The use of the most suitable sewing machine has an utmost importance in the profitability and effectiveness of sewing operations. In this study, LPP was employed in order to solve the sewing machine selection problem faced by a textile company. A ranking of eight alternative industrial sewing machines was obtained based on the preferences of company managers. ISM 1 is proposed as the best sewing machine since it has the lowest total score.

Although LPP allows the decision maker to express his/her preferences using physically meaningful values it cannot consider the uncertainty and vagueness associated with decision maker's preferences. That is why development of a sewing machine selection approach based on fuzzy linear physical programming can be an interesting future research topic.

\section{REFERENCES}

1. Silva LF, Lima M, Carvalho H, Rocha AM, Ferreira FN, Monteiro JL, Couto C. 2003. Actuation, monitoring and closed-loop control of sewing machine presser foot. Transactions of the Institute of Measurement and Control 25 (5), 419-432.

2. Syduzzaman M, Golder AS, 2015. Apparel analysis for layout planning in sewing section. International Journal of Current Engineering and Technology 5 (3), 1736-1742.

3. Ertuğrul I, Öztaş T. 2015. The application of sewing machine selection with the multi-objective optimization on the basis of ratio analysis method (moora) in apparel sector. Tekstil ve Konfeksiyon 25 (1), 80-85.

4. Ulutaş A. 2017. Sewing machine selection for a textile workshop by using edas method. Journal of Business Research-Türk 9 (2), 169-183.

5. Messac A, Gupta S, Akbulut B. 1996. Linear physical programming: a new approach to multiple objective optimization. Transactions on Operational Research 8 (2), 39-59.

6. Ilgin MA, Gupta SM, 2012. Physical programming: A review of the state of the art". Studies in Informatics and Control 21 (4), 349-366.
7. Messac A. 2015. Optimization in practice with matlab: for engineering students and professionals. Cambridge University Press, New York.

8. Ilgin MA, Gupta SM. 2012. Remanufacturing modeling and analysis. CRC Press, Boca Raton.

9. Gulsun B, Tuzkaya G, Tuzkaya UR, Onut S. 2009. An aggregate production planning strategy selection methodology based on linear physical programming. International Journal of Industrial Engineering 16 (2), 135-146.

10. Pochampally KK, Gupta SM. 2012. Use of linear physical programming and bayesian updating for design issues in reverse logistics. International Journal of Production Research 50 (5), 13491359.

11. Ilgin MA. 2017. Integrating linear physical programming and fuzzy logic for robot selection. International Journal of Robotics Applications and Technologies 5 (2), 1-17. 